\title{
Death and long-term disability after gun injury: a cohort analysis
}

\author{
Sheharyar Raza MD, Deva Thiruchelvam MSc, Donald A. Redelmeier MD MS(HSR)
}

Abstract

Background: Gun injury accounts for substantial acute mortality worldwide and many others survive with lingering disabilities. We investigated whether additional health losses beyond mortality can also arise for patients who survive with long-term disability.

Methods: We conducted a population-based individual patient analysis of adults injured by firearms who had received emergency medical care in Ontario, Canada, from Apr. 1, 2002, to Apr. 1, 2019. Longitudinal cohort analyses were evaluated through deterministic linkages of individual electronic patient files. The primary outcome was death or subsequent application for longterm disability in the years after hospital discharge.

Results: In total, 8313 patients were injured from firearms, of which 3020 were injured from intentional incidents and 5293 were injured from unintentional incidents. A total of 2657 (88.0\%) patients with intentional gun injury and 5089 (96.1\%) patients with unintentional gun injury survived initial injuries. After a mean 7.75 years of follow-up, patients surviving intentional injuries had a disability rate twice as high as patients surviving unintentional injuries $(19.7 \%$ v. $10.1 \%, p<0.001)$, equivalent to a hazard ratio of 2.01 (95\% confidence interval 1.80-2.25). The higher risk of long-term disability for survivors after intentional gun injury was not explained by demographic characteristics, extended to survivors treated and released from the emergency department, and was observed regardless of whether the incident was self-inflicted or from interpersonal assault. Half of the disability cases were identified after the first year. Additional predictors of long-term disability included a lower socioeconomic status, an urban home location, arrival by ambulance transport, a history of mental illness and a diagnosis of substance use disorder.

Interpretation: Our study shows that gun death statistics underestimate the extent of health losses from long-term disability, particularly for those with intentional injuries. Additional and sustainable follow-up medical care might improve patient outcomes.

uns can be useful for hunting excursions, sport shooting and self-defence. Canadians living in wilderness regions rely on guns for securing food and protecting themselves against animal attacks. ${ }^{1}$ However, a large downside of guns is the risk of injury. In Canada, mortality from gun injuries amounts to 800 total deaths annually, equivalent to a rate of 23 deaths per million per year. ${ }^{2}$ An estimated 700 fewer Canadians would die from gun injury each year if per capita mortality rates in Canada matched those in the United Kingdom. ${ }^{3,4}$ Some countries have a higher mortality from gun injuries, including the United States with a rate of about 200 deaths per million population per year.

Many people survive gun injury, which means mortality rates may underestimate the total health losses. ${ }^{6}$ For example, some patients with through-and-through brain injuries (i.e., from a bullet that has passed through leaving entry and exit wounds) stay alive but reside in long-term care institutions. ${ }^{7}$ The intensity of pain or neurologic deficits associated with gun injury can be severe and lasting. ${ }^{8} \mathrm{Up}$ to half of those with gun injury show anxiety, depression or other signs of stress while in hospital. ${ }^{9,10}$ Disfigurement can lead to further complications. ${ }^{11}$ Conversely, some patients view survivorship as a source of personal pride, community prestige or divine intervention. ${ }^{12,13}$ However, aside from reports after military combat, rigorous studies are near-silent about long-term prognosis and instead focus on acute care survival. ${ }^{14-16}$

The aim of this study was to examine whether the risks of death and long-term disability are substantial after gun injury, contrary to the rapid recoveries depicted in some action movies. Moreover, we hypothesized that intentional gun injury, relative to unintentional gun injury, would lead to a greater burden of long-term disability because of the differences in wound anatomy, patient characteristics, injury circumstances, trauma severity, counterfactual reasoning, psychological outrage and community supports. ${ }^{17-19}$ Herein we explore this distinction and apply population-wide health care databases to examine long-term outcomes for patients who survive gun injury.

\section{Competing interests: None declared.}

This article has been peer reviewed.

Correspondence to: Donald Redelmeier, dar@ices.on.ca

CMAJ Open 2020. DOI:10.9778/cmajo.20190200 


\section{Methods}

\section{Setting}

Ontario is Canada's most populous province, and had a population of 13069182 in 2010 (study midpoint) distributed over $1074845 \mathrm{~km}^{2}$ of land area (urban and rural). ${ }^{20,21}$ Health services data could be analyzed through individually linked populationbased databases at ICES. ${ }^{22-27}$ Emergency care was universally available with no user fees for all 178 hospitals in the province and the data could be tracked through encrypted linked ICES databases. ${ }^{24,28,29}$ Prevailing laws during the study period (Apr. 1, 2002, to Apr. 1, 2019) included a mandate for medical reporting of all patients who experienced gun injury. ${ }^{30}$ Diverse disability programs were available for adults older than 18 years, based on physician assessments that were included in ICES databases..$^{31}$ The population average incidence of disability is about 7 per 1000 people annually in this region. ${ }^{32}$

\section{Gun injury}

We identified adults aged 16 years or older injured by firearms and who had received emergency medical care between Apr. 1, 2002, and Apr. 1, 2019. These dates included all the years for which data were available in ICES databases and a minimum 1-year follow-up for nearly every patient. Past studies indicate that ICES databases are comprehensive (covering $>99 \%$ of emergency departments), connected (linkage rates $>95 \%$ ) and consistent (diagnostic reliability $>90 \%$ compared with chart abstraction). ${ }^{25,33,34}$ Diagnoses were based on the International Classification of Diseases as validated and used in past studies (codes W32-34, X72-74, X93-95 and $\mathrm{Y} 22-24) .{ }^{35-39} \mathrm{We}$ excluded those dead at the scene, those living outside of Ontario, those lacking a valid health card number and youth younger than 16 years (eligibility age for disability support). Patients with more than 1 injury were analyzed by first presentation to avoid statistical artifacts from trauma recidivism. ${ }^{40}$

\section{Additional characteristics}

Data on patient age (years), sex (binary), socioeconomic status (quintile) and home location (urban, rural) were based on linked demographic databases. ${ }^{26,41,42}$ Additional databases identified incident time (year, season, hour), firearm type (hand gun, long gun, uncertain) and whether the patient arrived by ambulance (air or ground). ${ }^{29}$ Intentional injuries (self-inflicted, assault) were defined by diagnostic codes with uncertain cases presumed unintentional. ${ }^{43,44} \mathrm{We}$ further searched outpatient databases in the prior year to identify earlier psychiatric illnesses and diagnosis of substance use disorder. ${ }^{45}$ General health care use indicators in the prior year also included total hospital admissions, emergency visits and outpatient contacts as proxies for comorbidity. ${ }^{46,47}$

\section{Acute care}

We examined short-term clinical outcomes for secondary descriptive analyses to corroborate past studies..$^{18,48-50}$ Hospital mortality included patients who died in the emergency department, during initial hospital admission or after transfer to a specialized trauma centre.$^{51}$ Hospital length of stay indicated the total time in days from arrival in the emergency department to death, discharge or departure (including patients who left against medical advice). ${ }^{52}$ The number of operations, use of transfusion products and days in intensive care were identified, taking into account those who had none. The available ICES databases lacked information on race, injury circumstances, bullet calibre, vital signs, imaging scans, functional status, formal education and criminal records. ${ }^{53}$

\section{Primary outcome}

The primary outcome was subsequent death or long-term disability (i.e., submission of a new disability support application) for patients who survived initial injury. We considered disability as the dominant outcome along with death as a competing risk (each component also tested in secondary analysis). Such disability support applications included a medical report (Health Status Report, Activities of Daily Living Index, Special Necessities Benefit Form) and involved the patient's physician. In turn, the submission of a medical report allowed tracking of applications using Ontario Health Insurance Plan codes (K050-K054). ${ }^{54,55}$ The available databases lacked information on social supports and financial programs accessed by patients.

We defined disability as the submission of a new disability support application because the document was available, measurable, authenticated and incorporated the patient's perspective. ${ }^{55}$ These techniques have been validated in past research yet can undercount disability because of patients who are reluctant to complain or hesitate to file a claim. ${ }^{56} \mathrm{We}$ defined the date of disability by the submission of the application because this time was available, objective and served as a marker for the realization that full recovery might not occur. The available databases did not contain information on the reasons for disability, supports received or how it directly connected to the original gun injury.

\section{Statistical analysis}

In our primary comparison, we tested whether the risk of disability in the years following gun injury is higher for those with intentional injuries compared with those with unintentional injuries. We defined the follow-up interval as starting on the day of hospital departure and included only those who survived initial injuries. We used unadjusted cumulative incidence curves to evaluate survivors for death or disability during the decade following injury. ${ }^{57} \mathrm{We}$ further examined the relative risk of death and disability for the full cohort of survivors before and after adjusting for additional measured baseline characteristics using the Fine and Gray model of competing risks (subdistributional hazard ratios used as the estimate of relative risks). ${ }^{58-61}$ No data imputation methods were used.

\section{Ethics approval}

The study protocol was approved by the Sunnybrook Research Ethics Board, including a waiver for direct individual patient consent. 


\section{Results}

In total, 8313 individuals were injured by firearms and received emergency medical care during the 17 -year study period. Of the total injuries, $63.7 \%$ were unintentional injuries and $36.3 \%$ were intentional injuries (Table 1). Both groups mainly consisted of men younger than 30 years, and the individuals were widely distributed across socioeconomic status quintiles. Patients with intentional injuries, relative to those with unintentional injuries, tended to live in a city, have an uncertain weapon type and arrive by ambulance transport. Injuries occurring on the weekends were frequent in both groups and a nighttime incident was disproportionately frequent for those with intentional injuries (Appendix 1A, available at www.cmajopen.ca/content/8/3/E469/supp1/DC1). A minority in both groups had a past hospital admission or a past mental health diagnosis.

\section{Acute care outcomes}

A total of 2430 patients were admitted to hospital (Table 2). Among those admitted to hospital, about two-thirds required a surgical procedure, one-third required critical care, and a quarter of those admitted to hospital received transfusion products. In total, the cohort accounted for 6191 days in critical care and 24577 days of hospital stay.

The general profile of short-term acute hospital care suggested a greater severity of injury for patients with intentional incidents compared with those with unintentional incidents, as measured by hospital admission rates, surgical procedures, critical care, blood transfusions, mean days in hospital and risk of acute death (Table 2). A total of 2657 patients with intentional gun injury and 5089 patients with unintentional gun injury survived initial injuries.

\section{Subsequent risk of disability}

The 7746 total survivors accounted for 60098.6 patient-years of follow-up (mean $7.75 \mathrm{yr}$ ). Patients surviving intentional gun injury accounted for 584 subsequent cases of disability over 17669.4 patient-years of follow-up (mean $6.65 \mathrm{yr}$ ), equal to an incidence of 33 per 1000 patients annually. Patients surviving unintentional gun injury accounted for 639 subsequent cases of disability over 42429.2 patient-years of follow-up (mean $8.34 \mathrm{yr}$ ), equal to an incidence of 15 per 1000 patients annually. Taken together, intentional gun injury was associated with an increased risk of subsequent disability relative to unintentional gun injury (disability rate $19.7 \%$ v. $10.1 \%$, respectively, $p<0.001$; hazard ratio [HR] 2.01, 95\% confidence interval [CI] 1.80-2.2.5). For both groups, half the disability cases appeared after the first year (Figure 1).

\section{Additional predictors}

The risk of subsequent disability associated with gun injury was also related to patient characteristics. Lower socioeconomic status, an urban home location, a nighttime incident time and ambulance arrival were each associated with higher risks (Table 3). A past diagnosis of mental illness or of substance use disorder or a recent emergency department visit was also associated with higher risks. Conversely, patient age and sex were not significant predictors. The day of the week or the season were also not significant predictors. Adjustment for all measured patient characteristics suggested that intentional gun injury was associated with an increased risk of subsequent disability relative to unintentional gun injury (HR $1.40,95 \%$ CI $1.24-1.60)$.

\section{Secondary analyses}

The higher relative risk of subsequent disability associated with intentional gun injury relative to those with unintentional gun injury extended to important subgroups. In particular, a higher risk was observed for patients treated and released from the emergency department and for patients admitted to hospital (Appendix 1B). Similarly, a higher risk was observed regardless of a history of mental illness, substance use disorder, firearm weapon type, ambulance involvement, health care in the prior year or length of hospital stay. A higher risk was consistent for incidents that were selfinflicted and for incidents from interpersonal assault. No subgroup showed contrary findings and all subgroups with more than 1000 patients showed a significant higher relative risk.

\section{Subsequent mortality}

The higher risks of subsequent disability associated with intentional gun injury were also observed for long-term mortality, although the absolute counts were modest (Figure 2). Patients surviving intentional gun injury accounted for 137 subsequent deaths, equal to an incidence of 8 per 1000 patients annually. Patients surviving unintentional gun injury accounted for 156 subsequent deaths, equal to an incidence of 4 per 1000 patients annually. Taken together, intentional gun injury was associated with an increased risk of mortality relative to unintentional gun injury (HR 1.85, 95\% CI 1.47-2.33). Additional predictors of subsequent mortality included older age, lower socioeconomic status, an incident occurring at night and a diagnosis of mental illness (Table 3).

\section{Interpretation}

We studied gun injury to assess the long-term risks of disability. We found that most patients survived during the initial hospital stay and many later became disabled. The risk of long-term disability was substantial, amounting to more than 1 in 5 patients with intentional injuries and 1 in 10 patients with unintentional injuries. The higher relative risk of longterm disability following intentional gun injury was not fully explained by baseline patient demographic characteristics, occurred regardless of whether the incident was self-inflicted or from interpersonal assault, and extended to those who were not admitted to hospital. Taken together, these data suggest that mortality statistics underestimate the effects of gun injury because many patients do not lose their lives, but lose their livelihoods. ${ }^{62,63}$

Our study supports past reports of long-term outcomes after other forms of injury. A retrospective cohort study in a Baltimore population evaluated all adult trauma patients over 


\section{Research}

Table 1: Characteristics of $\mathbf{8 3 1 3}$ patients with intentional or unintentional gun injury who received emergency medical care during the study period

\begin{tabular}{|c|c|c|}
\hline \multirow[b]{2}{*}{ Characteristic } & \multicolumn{2}{|c|}{ No. $(\%)$ of patients } \\
\hline & $\begin{array}{c}\text { Intentional }^{*} \\
n=3020\end{array}$ & $\begin{array}{c}\text { Unintentional } \\
n=5293\end{array}$ \\
\hline \multicolumn{3}{|l|}{ Demographic } \\
\hline \multicolumn{3}{|l|}{ Age, yr } \\
\hline$<30$ & $1857(61.5)$ & $3178(60.0)$ \\
\hline$\geq 30$ & $1163(38.5)$ & $2115(40.0)$ \\
\hline \multicolumn{3}{|l|}{ Sex } \\
\hline Male & 2754 (91.2) & 4756 (89.9) \\
\hline Female & $266(8.8)$ & $537(10.1)$ \\
\hline \multicolumn{3}{|l|}{ Home } \\
\hline Urban & $2759(91.4)$ & $4270(80.7)$ \\
\hline Rural & $261(8.6)$ & $1023(19.3)$ \\
\hline \multicolumn{3}{|c|}{ Socioeconomic quintile† } \\
\hline 5 (highest) & $250(8.3)$ & 705 (13.3) \\
\hline 4 & $356(11.8)$ & $853(16.1)$ \\
\hline 3 & $517(17.1)$ & $1034(19.5)$ \\
\hline 2 & $716(23.7)$ & $1067(20.2)$ \\
\hline 1 (lowest) & 1181 (39.1) & $1634(30.9)$ \\
\hline \multicolumn{3}{|c|}{ Past year health care } \\
\hline \multicolumn{3}{|c|}{ Hospital admission } \\
\hline Yes & $92(3.0)$ & $119(2.2)$ \\
\hline No & $2928(97.0)$ & $5174(97.8)$ \\
\hline \multicolumn{3}{|c|}{ Emergency visit } \\
\hline Yes & $1087(36.0)$ & 2095 (39.6) \\
\hline No & $1933(64.0)$ & $3198(60.4)$ \\
\hline \multicolumn{3}{|c|}{$\geq 7$ outpatient visits } \\
\hline Yes & $342(11.3)$ & $509(9.6)$ \\
\hline No & $2678(88.7)$ & $4784(90.4)$ \\
\hline \multicolumn{3}{|c|}{ Substance use disorder diagnosisł } \\
\hline Yes & $221(7.3)$ & $289(5.5)$ \\
\hline No & $2799(92.7)$ & $5004(94.5)$ \\
\hline \multicolumn{3}{|c|}{ Mental health diagnosis§ } \\
\hline Yes & $698(23.1)$ & $1086(20.5)$ \\
\hline No & $2322(76.9)$ & $4207(79.5)$ \\
\hline \multicolumn{3}{|l|}{ Acute incident } \\
\hline \multicolumn{3}{|l|}{ Weapon } \\
\hline Hand gun & $63(2.1)$ & $238(4.5)$ \\
\hline Long gun & $25(0.8)$ & $422(8.0)$ \\
\hline Uncertain & $2932(97.1)$ & $4633(87.5)$ \\
\hline \multicolumn{3}{|l|}{ Ambulance } \\
\hline Yes & $2055(68.0)$ & $1284(24.3)$ \\
\hline No & $965(32.0)$ & $4009(75.7)$ \\
\hline \multicolumn{3}{|c|}{$\begin{array}{l}\text { Note: OHIP = Ontario Health Insurance Plan. } \\
\text { "Denotes self-inflicted (codes X6., X7., X80-X84) or assault (codes X85- X89, X9., Y0.). } \\
\text { †Based on Statistics Canada algorithm. } \\
\text { †OHIP diagnostic codes } 303 \text { to } 304 \text {. } \\
\text { §OHIP diagnostic codes } 290 \text { to } 316 \text { (except 293, 294, 303, 304, 308, 310, 312). }\end{array}$} \\
\hline
\end{tabular}


Table 2: Acute hospital care in $\mathbf{8 3 1 3}$ patients with intentional or unintentional gun injury who received emergency medical care during the study period

\begin{tabular}{|c|c|c|}
\hline \multirow[b]{2}{*}{ Characteristic } & \multicolumn{2}{|c|}{ No. $(\%)$ of patients* } \\
\hline & $\begin{array}{c}\text { Intentional } \\
n=3020\end{array}$ & $\begin{array}{c}\text { Unintentional } \\
n=5293\end{array}$ \\
\hline \multicolumn{3}{|l|}{ Hospital admission } \\
\hline Yes & $1638(54.2)$ & $792(15.0)$ \\
\hline No & $1382(45.8)$ & $4501(85.0)$ \\
\hline \multicolumn{3}{|l|}{ Surgical procedure } \\
\hline Yes & $1060(35.1)$ & $538(10.2)$ \\
\hline No & $578(19.1)$ & $254(4.8)$ \\
\hline No admission & $1382(45.8)$ & $4501(85.0)$ \\
\hline \multicolumn{3}{|l|}{ Critical care unit } \\
\hline Yes & $756(25.0)$ & $266(5.0)$ \\
\hline No & $882(29.2)$ & $526(9.9)$ \\
\hline No admission & $1382(45.8)$ & $4501(85.0)$ \\
\hline \multicolumn{3}{|l|}{ Blood transfusion† } \\
\hline Yes & $457(15.1)$ & $176(3.3)$ \\
\hline No & 1181 (39.1) & $616(11.6)$ \\
\hline No admission & $1382(45.8)$ & $4501(85.0)$ \\
\hline \multicolumn{3}{|l|}{ Time in hospital } \\
\hline No. of days, median (IQR) & $6(3-11)$ & $5(2-10)$ \\
\hline No admission & - & - \\
\hline \multicolumn{3}{|l|}{ Outcomeł } \\
\hline Death & $363(12.0)$ & $204(3.9)$ \\
\hline Alive & 2657 (88.0) & $5089(96.1)$ \\
\hline \multicolumn{3}{|c|}{$\begin{array}{l}\text { Note: IQR = interquartile range. } \\
\text { *Unless stated otherwise. } \\
\text { †Based on packed red cells, platelets or whole blood. } \\
\text { †Excludes deaths at the scene and includes short-term emergency and hospital } \\
\text { care. }\end{array}$} \\
\hline
\end{tabular}

10 years and found a $15 \%$ risk of hospital mortality after gun injury. ${ }^{64}$ In contrast, the relatively lower $7 \%$ hospital mortality observed in our study may be partially attributable to a smaller number of intentional incidents with reduced injury severity. Additional studies of mortality spanning similar longterm follow-up show a comparable risk of long-term mortality despite the overall decline in hospital case fatality rates..$^{65,66}$ Readmissions for delayed complications are also commonly reported in case series analyses of patients after gun injury, with a majority occurring after the first year postdischarge. ${ }^{62}$

Systematic investigations of quality of life after gun injury are relatively sparse, typically based on small select samples, and tend to use qualitative survey responses. One study conducted by telephone interviews years after hospital discharge found that about half the patients had physical limitations and nearly two-thirds experienced psychological illnesses following gun injury. ${ }^{67}$ The risks of long-term disability were further accentuated in patients of lower socioeconomic status. ${ }^{68}$
These self-reported findings agree with the high prevalence of long-term disability observed in our study. To our knowledge, there are no systematic studies of long-term disability after gun injury in a Canadian population, and international literature repeatedly highlights the gaps in the scientific understanding of long-term outcomes for patients after gun injury. ${ }^{69,70}$

The uncertain reasons underlying long-term disability suggest the need for a multimodal approach to trauma survivorship. ${ }^{71}$ This might include follow-up care from surgeons, psychiatrists, family physicians, physiotherapists, social workers, occupational therapists, spiritual care workers and other allied professionals. ${ }^{72}$ Current clinical care does not abandon patients; however, our study suggests that the prevailing efforts are not sufficient. Future clinical priorities could include additional management of pain, depression, anxiety, sleep and substance use disorder. ${ }^{73-75}$ Additional counselling might also be necessary for workforce participation, including a role for a navigator to negotiate between a disabled survivor and a potential employer. ${ }^{76}$ To the best of our knowledge, no trauma centre offers such a holistic follow-up clinic for adults after gun injury. ${ }^{77,78}$ Our study highlights a substantial need to support survivors. ${ }^{79}$

Future research based on additional data sources might be justified as opportunities to address these and other uncertainties. ${ }^{80,81}$ These studies might include broad surveys of clinical treatments and unmet health care needs over time. ${ }^{82}$ An alternative approach can be an evidence-based social network analysis of social dynamics among survivors over time..$^{83}$ Further investigations might examine specific risk factors for gun injury and predictive factors for recovery outcomes. ${ }^{84} \mathrm{~A}$ more controversial line of study can test the subjective nature of disability and the fallible determinations of severity ${ }^{85}$ Additional opportunities might also include analyses of governmental and consumer databases from other countries. ${ }^{86}$

\section{Limitations}

Our study has many limitations. The patients were mostly injured in isolated incidents and this provides little insight about gang violence or mass casualty events. ${ }^{87-89}$ The data were based on a large high-income region and may underestimate losses in low-resource settings. Our data may also underestimate losses owing to fallibility in identifying intentional injuries. ${ }^{3}$ The study does not account for patients who died at the scene, those who moved away (and were assumed fine) or those harmed by a culture of fear. ${ }^{70,90}$ Disability data may also underestimate additional losses from missed days at work, career advancement, family relationships, emotional distress, trauma recidivism and financial costs. ${ }^{91,92}$ The design was an observational analysis and cannot establish whether a correlation indicates possible causality $(\mathrm{E}$-value $=2.80) .{ }^{93-96}$

The findings may be also prone to misquotation in public debates about firearms. ${ }^{97}$ Specifically, the observed risks of long-term disability do not directly prove or disprove calls for gun control. ${ }^{98}$ The study does not address safe storage, background checks, licensing policies, waiting periods, safety training or other particular injury prevention strategies..$^{99,100}$ 


\section{Research}

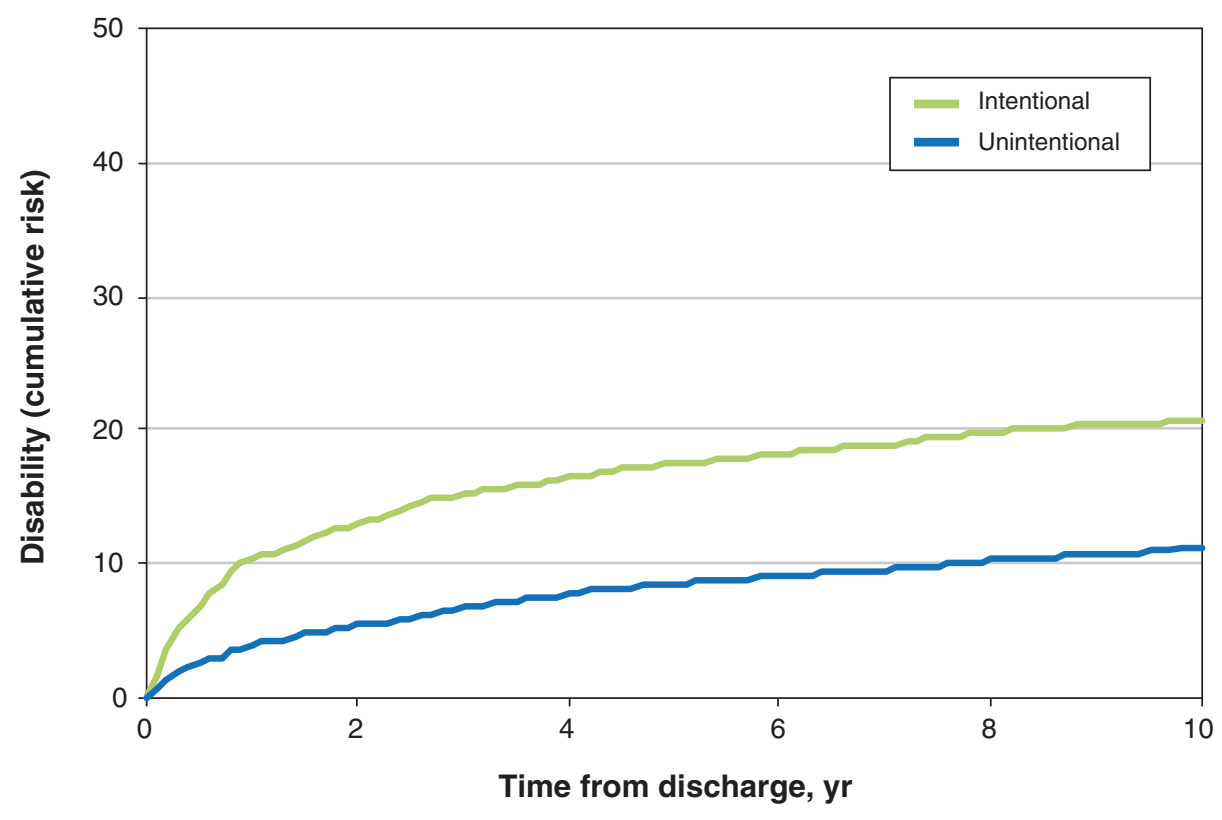

Figure 1: Risk of subsequent disability. Cumulative incidence plots of absolute risk of disability following injury.

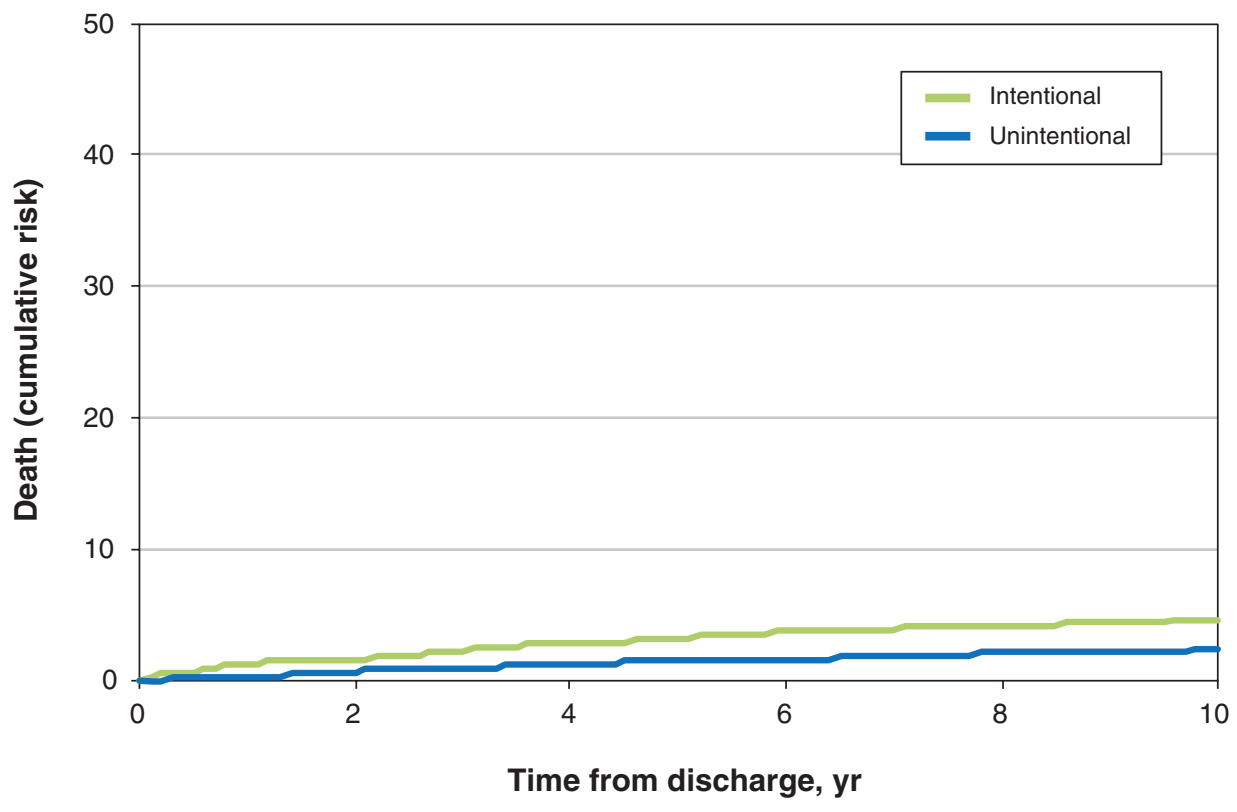

Figure 2: Risk of subsequent death. Cumulative incidence plots of absolute risk of death following injury. 
Table 3: Predictors of disability after gun violence*

\begin{tabular}{|c|c|c|}
\hline \multirow[b]{2}{*}{ Characteristic } & \multicolumn{2}{|c|}{ Relative risk $(95 \% \mathrm{Cl})$} \\
\hline & Basic analysis† & Adjusted analysisł \\
\hline \multicolumn{3}{|l|}{ Acute injury } \\
\hline Intentional injury & $2.01(1.80-2.25)$ & $1.40(1.24-1.60)$ \\
\hline \multicolumn{3}{|l|}{ Age group } \\
\hline Younger (Ref. $\geq 30$ yr) & $0.96(0.85-1.07)$ & $\S$ \\
\hline \multicolumn{3}{|l|}{ Sex } \\
\hline Male & $0.95(0.79-1.14)$ & $\S$ \\
\hline \multicolumn{3}{|l|}{ Home location (Ref. = rural) } \\
\hline Urban & $1.86(1.54-2.25)$ & $1.48(1.22-1.80)$ \\
\hline \multicolumn{3}{|c|}{ Socioeconomic quintile (Ref. = middle) } \\
\hline Highest & $0.81(0.67-0.98)$ & $0.86(0.70-1.04)$ \\
\hline Lowest & $1.52(1.30-1.78)$ & $1.39(1.19-1.63)$ \\
\hline \multicolumn{3}{|c|}{ Incident season (Ref. = summer) } \\
\hline Autumn & $0.91(0.79-1.06)$ & $\S$ \\
\hline Winter & $1.05(0.90-1.24)$ & $\S$ \\
\hline Spring & $1.04(0.89-1.21)$ & $\S$ \\
\hline \multicolumn{3}{|c|}{ Incident day (Ref. = weekday) } \\
\hline Weekend & $1.07(0.95-1.20)$ & $\S$ \\
\hline \multicolumn{3}{|c|}{ Incident hour (Ref. = afternoon) } \\
\hline Morning & $1.09(0.92-1.28)$ & $1.03(0.87-1.22)$ \\
\hline Night & $1.32(1.17-1.50)$ & $1.08(0.95-1.23)$ \\
\hline \multicolumn{3}{|l|}{ Ambulance transport } \\
\hline Yes & $2.21(1.98-2.47)$ & $1.76(1.55-1.99)$ \\
\hline \multicolumn{3}{|l|}{ History } \\
\hline \multicolumn{3}{|l|}{ Hospital admission in past } \\
\hline Yes & $1.33(0.90-1.95)$ & $\S$ \\
\hline \multicolumn{3}{|l|}{ Emergency visit in past } \\
\hline Yes & $1.23(1.10-1.38)$ & $1.16(1.03-1.31)$ \\
\hline \multicolumn{3}{|l|}{ Outpatient visits in past } \\
\hline Count & $1.02(1.02-1.03)$ & $1.01(1.00-1.01)$ \\
\hline \multicolumn{3}{|c|}{ Mental health diagnosis in past } \\
\hline Yes & $1.92(1.70-2.17)$ & $1.67(1.47-1.91)$ \\
\hline \multicolumn{3}{|l|}{ Substance abuse in past } \\
\hline Yes & $2.43(2.04-2.89)$ & $1.62(1.32-1.99)$ \\
\hline $\begin{array}{l}\text { Note: } \mathrm{Cl}=\text { confidence interval, } \\
\text { *Estimates based on Fine and } \\
\text { †No adjustment for baseline dif } \\
\text { †Adjusted for all measures sign } \\
\text { §Denotes estimates not signific }\end{array}$ & Arviving acute gun viole & \\
\hline
\end{tabular}

The analysis provides no data on the benefits of gun ownership for those who gain security and experience no adverse incidents. ${ }^{101}$ The specific data on determining firearm type are difficult to interpret because of the large number of cases with missing information. The research cannot settle the unceasing tension between safety and liberty because moral imperatives extend beyond a biomedical perspective. ${ }^{102-104}$

An additional caveat is that our data do not explain mechanisms by which gun injury might lead to higher disability after intentional rather than unintentional incidents. Many 
biomedical and social factors could contribute to these mechanisms including severity of injury, preexisting illnesses and background community supports. ${ }^{105-108}$ Another potential contributor is the fear of being labelled from identifying as a victim, which may lead to reduced self-esteem, decreased selfefficacy and depression. . $^{709-111}$ A further possibility may be the nature of blame, concepts of responsibility and a negative spiral of disempowerment with anxiety. ${ }^{112-114}$ A different explanation might be a statistical artifact from fallible ascertainment of intent leading to misclassification bias.

\section{Conclusion}

Gun inujury causes considerable mortality yet many patients survive with long-term disability. The long-term risks of disability are particularly accentuated for survivors after intentional injuries.

\section{References}

1. Why own a gun? Protection is now top reason. Washington (D.C.): Pew Research Center; 2013 Mar. 12. Available: www.people-press.org/2013/03/12/ why-own-a-gun-protection-is-now-top-reason/ (accessed 2019 Sept. 1).

2. Cotter A. Firearms and violent crime in Canada, 2012. Ottawa: Statistics Canada; 2012. Cat no 85-002-X. Available: https://www150.statcan.gc.ca/n1/pub/85 -002-x/2014001/article/11925-eng.htm (accessed 2019 Feb. 12).

3. Yanchar NL, Beno S; Canadian Association of Emergency Physicians and the Trauma Association of Canada. Can we do better?: A Canadian perspective on firearm injury prevention. Ann Surg 2018;267:1009-10.

4. Nand D, Naghavi M, Marczak LB, et al. Global mortality from firearms, 1990-2016. 7AMA 2018;320:792-814.

5. WHO Mortality Data Base. Geneva: World Health Organization Department of Health Statistics and Information Systems; updated 2018 May. Available: http:// apps.who.int/healthinfo/statistics/mortality/causeofdeath_query/ (accessed 2019 Feb. 12).

6. Corso PS, Mercy JA, Simon TR, et al. Medical costs and productivity losses due to interpersonal and self-directed violence in the United States. Am 7 Prev Med 2007;32:474-82.

7. Raza S, Redelmeier DA. Gunshot to the head. Am F Med 2018;131:e7-8.

8. Ajmal S, Enam SA, Shamim MS. Neurogenic claudication and radiculopathy as delayed presentations of retained spinal bullet. Spine 7 2009;9:e5-8.

9. Wiseman T, Foster K, Curtis K. Mental health following traumatic physical injury: an integrative literature review. Injury 2013;44:1383-90.

10. Disaster Technical Assistance Center Supplemental Research Bulletin: Mass violence and behavioral health. Rockville (MD): Substance Abuse and Mental Health Services Administration; 2017:1-18. Available: https://www.samhsa. gov/sites/default/files/dtac/srb-mass-violence-behavioral-health.pdf (accessed 2019 July 26).

11. Smith RN, Seamon MJ, Kumar V, et al. Lasting impression of violence: retained bullets and depressive symptoms. Injury 2018;49:135-40.

12. Lee J. Wounded: life after the shooting. Ann Am Acad Pol Soc Sci 2012;642: 244-57.

13. Eligon J. One bullet can kill, but sometimes 20 don't, survivors show. The New York Times 2008 Apr. 3. Available: https://www.nytimes.com/2008/04/03/ nyregion/03shot.html (accessed 2019 July 26 ).

14. Ringburg AN, Polinder S, Van Ierland MCP, et al. Prevalence and prognostic factors of disability after major trauma. 7 Trauma 2011;70:916-22.

15. Laughlin MD, Belmont PJ, Lanier PJ, et al. Occupational outcomes following combat-related gunshot injury. Int 7 Surg 2017;48:286-90.

16. Stevenson T, Carr DJ, Penn-Barwell JG, et al. The burden of gunshot wounding of UK military personnel in Iraq and Afghanistan from 2003-14. Injury 2018;49:1064-9.

17. Redelmeier DA, Blair PJ. Survivors of motor vehicle trauma - an analysis of seat belt use and health care utilization. F Gen Intern Med 1993;8:199-203.

18. Mills BM, Nurius PS, Matsueda RL, et al. Prior arrest, substance use, mental disorder, and intent-specific firearm injury. Am 7 Prev Med 2018;55:298-307.

19. Rattan R, Parreco J, Namias N, et al. Hidden costs of hospitalization after firearm injury: national analysis of different hospital readmission. Ann Surg 2018;267:810-5.

20. Canada at a glance 2010 - population. Ottawa: Statistics Canada; 2010. Available: https://www150.statcan.gc.ca/n1/pub/12-581-x/2010000/pop-eng.htm (accessed 2019 Mar. 17).

21. About Ontario. Toronto: Government of Ontario; 2019. Available: https:// www.ontario.ca/page/about-ontario (accessed 2019 Mar. 17).
22. van Walraven CV, Paterson JM, Kapral M, et al. Appropriateness of primary total hip and knee replacements in regions of Ontario with high and low utilization rates. CMAF 1996;155:697-706.

23. Iron K, Manuel DG. Quality assessment of administrative data (QuAAD): an opportunity for enhancing Ontario's health data. Toronto: ICES; 2007.

24. Iron K, Zagorski B, Sykora K. Living and dying in Ontario: an opportunity for improved health information - ICES investigative report. Toronto: ICES; 2008. Available: https://www.ices.on.ca/Publications/Atlases-and-Reports /2008/Living-and-dying-in-Ontario (accessed 2019 July 26).

25. Chiu M, Lebenbaum M. Lam K, et al. Describing the linkages of the immigration, refugees and citizenship Canada permanent resident data and vital statistics death registry to Ontario's administrative health database. BMC Med Inform Decis Mak 2016;16:135.

26. Data dictionary. Toronto: ICES; 2019. Available: https://datadictionary.ices. on.ca/Applications/DataDictionary/Default.aspx (accessed 2020 Feb. 11).

27. Working with ICES data. Toronto: ICES. Available: www.ices.on.ca/Data -and-Privacy/ICES-data/Working-with-ICES-Data (accessed 2020 Feb. 11).

28. Chan B, Schull MJ, Schultz SE. Atlas report: emergency department services in Ontario. Toronto: ICES; 2001. Available: https://www.ices.on.ca/flip -publication/emergency-department-services-in-ontario/files/assets/basic-html /index.html\#54 (accessed 2019 July 26).

29. NACRS emergency department visits and length of stay, 2017-2018 [National Ambulatory Care Reporting System]. Ottawa: Canadian Institute for Health Information; 2019. Available: https://www.cihi.ca/en/quick-stats (accessed 2019 Mar. 17).

30. Kondro W. Gunshot wound reporting mandatory in Ontario. CMAf 2005;173:242-242-a.

31. Ministry of Community and Social Services. Ontario Ministry of Children, Community and Social Services. Toronto; 2019. Available: https://www.mcss. gov.on.ca/en/mcss/ (accessed 2019 Mar. 17).

32. Morris S, Fawcett G, Brisebois L, et al. A demographic, employment and income profile of Canadians with disabilities aged 15 years and over, 2017. Ottawa: Statistics Canada; 2018. Cat no 89-654-X2018002. Available: https://www150.statcan. gc.ca/n1/pub/89-654-x/89-654-x2018002-eng.pdf (accessed 2019 July 26).

33. Data quality documentation, National Ambulatory Care Reporting System: current-year information, 2017-2018. Ottawa: Canadian Institute for Health Information, 2018. Available: https://www.cihi.ca/sites/default/files/document/ current-year-information-nacrs-2017-2018-en-web.pdf (accessed 2019 July 26).

34. Data quality study of Ontario emergency department visits for 2004-2005 executive summary. Ottawa: Canadian Institute for Health Information; 2007:1-22. Available: https://secure.cihi.ca/free_products/vol1_nacrs_executive _summary_nov2_2007.pdf (accessed 2019 July 26).

35. LeMier M, Cummings P, West TA. Accuracy of external cause of injury codes reported in Washington State hospital discharge records. Inj Prev 2001;7:334-8.

36. Juurlink D, Preyra C, Croxford R, et al. Canadian institute for health information discharge abstract database: a validation study. Toronto: ICES; 2006.

37. Macpherson AK, Schull MJ. Penetrating trauma in Ontario emergency departments: a population-based study. CFEM 2007;9:16-20.

38. Furlan JC, Fehlings MG. The National Trauma Registry as a Canadian spine trauma database: a validation study using an institutional clinical database. Neuroepidemiology 2011;37:96-101.

39. Altoijry A, Al-Omran M, Lindsay TF, et al. Validity of vascular trauma codes at major trauma centres. Can 7 Surg 2013;56:405-8.

40. Hulley SB, Cummings SR. Designing clinical research. Baltimore: Williams and Wilkins; 1988.

41. Postal code conversion file (PCCF), reference guide. Ottawa: Statistics Canada; 2017. Cat no 92-154-G. Available: www.canadapost.ca/cpc/assets/cpc/uploads/files/ marketing/2017-postal-code-conversion-file-reference-guide-en.pdf (accessed 2019 Feb. 11).

42. Income and earnings reference guide, 2006 census. Ottawa: Statistics Canada; 2006. Cat no 97-563-GWE2006003. Available: http://www12.statcan.gc.ca/ census-recensement/2006/ref/rp-guides/income-revenu-eng.cfm (accessed 2019 July 26).

43. Parachute. Ontario injury data report 2018. Toronto: Parachute; 2018.

44. Becker R, Silvi J, Ma Fat D, et al. A method for deriving leading causes of death. Bull World Health Organ 2006;84:297-304.

45. Ardal S. Health analyst's toolkit. Toronto: Ontario Ministry of Health and LongTerm Care; 2012. Available: http://www.health.gov.on.ca/english/providers/ pub/healthanalytics/health_toolkit/health_toolkit.pdf (accessed 2019 July 26).

46. Discharge abstract database. Ottawa: Canadian Institute for Health Information; 2019. Available: https://www.cihi.ca/en/discharge-abstract-database-metadata (accessed 2019 July 26).

47. Drucker AM, Thiruchelvam D, Redelmeier DA. Eczema and subsequent suicide: a matched case-control study. BMF Open 2018;8:e023776.

48. Newgard CD, Sanchez BJ, Bulger EM, et al. A geospatial analysis of severe firearm injuries compared to other injury mechanisms: event characteristics, location, timing, and outcomes. Acad Emerg Med 2016;23:554-65.

49. Gani F, Sakran JV, Canner JK. Emergency department visits for firearmrelated injuries in the United States, 2006-14. Health Aff (Millwood) 2017; 36:1729-38

50. Sauaia A, Gonzalez E, Moore HB, et al. Fatality and severity of firearm injuries in a denver trauma center, 2000-2013. FAMA 2016;315:2465-7. 
51. Saunders NR, Lee H, Macpherson A, et al. Risk of firearm injuries among children and youth of immigrant families. CMA7 2017;189:E452-8.

52. Kapral MK, Fang J, Chan C, et al. Neighborhood income and stroke care and outcomes. Neurology 2012;79:1200-7.

53. Riddell CA, Harper S, Cerda M, et al. Comparison of rates of firearm and non-firearm homicide and suicide in black and white non-Hispanic men, by U.S. State. Ann Intern Med 2018;168:712-20.

54. Ontario Health Insurance Plan. Toronto: Ontario Ministry of Health and Long-Term Care; 2016. Available: http://www.health.gov.on.ca/en/public/ programs/ohip/ (accessed 2016 Oct. 12).

55. Ontario Health Insurance Plan: OHIP schedule of benefits and fees. Toronto: Government of Ontario Ministry of Health and Long-Term Care; 2018. Available: http://www.health.gov.on.ca/en/pro/programs/ohip/sob/ (accessed 2019 Mar. 17)

56. Reece SCM, Thiruchelvam D, Redelmeier DA. Medical emergencies in farmers. 7 Rural Health 2019;35:429-35.

57. Austin PC, Lee DS, Fine JP. Introduction to the analysis of survival data in the presence of competing risks. Circulation 2016;133:601-9.

58. Fine JP, Gray RJ. A proportional hazards model for the subdistribution of a competing risk. $\mathcal{F}$ Am Stat Assoc 1999;94:496-509.

59. Putter H, Fiocco M, Geskus RB. Tutorial in biostatistics: competing risks and multi-state models. Stat Med 2007;26:2389-430.

60. Lau B, Cole SR, Gange SJ. Competing risk regression models for epidemiologic data. Am 7 Epidemiol 2009; 170:244-56.

61. Austin PC, Fine JP. Practical recommendations for reporting Fine-Gray model analyses for competing risk data. Stat Med 2017;36:4391-400.

62. Wintemute GJ, Wright MA. Initial and subsequent hospital costs of firearm injuries. 7 Trauma 1992;33:556-60.

63. Gabbe BJ, Simpson PM, Harrison JE, et al. Return to work and functional outcomes after major trauma who recovers, when, and how well? Ann Surg 2016;263:623-32

64. Haider AH, Young JH, Kisat M, et al. Association between intentional injury and long-term survival after trauma. Ann Surg 2014;259:985-92.

65. Davidson GH, Hamlat CA, Rivara FP, et al. Long-term survival of adult trauma patients. 7 AMA 2011;305:1001-7.

66. Fahimi J, Larimer E, Hamud-Ahmed W, et al. Long-term mortality of patients surviving firearm violence. Inj Prev 2016;22:129-34.

67. Vella MA, Warshauer A, Tortorello G, et al. Long-term functional, psychological, emotional, and social outcomes in survivors of firearm injuries. $\mathscr{F} A M A$ Surg 2019;155:51-9.

68. Herrera-Escobar JP, Seshadri AJ, Rivero R, et al. Lower education and income predict worse long-term outcomes after injury. 7 Trauma Acute Care Surg 2019;87:104-10.

69. Bulger EM, Kuhls DA, Campbell BT, et al. Proceedings from the medical summit on firearm injury prevention: a public health approach to reduce death and disability in the US. 7 Am Coll Surg 2019;229:415-30.e12

70. Rowhani-Rahbar A, Zatzick DF, Rivara FP. Long-lasting consequences of gun violence and mass shootings. 7AMA 2019;321:1765-6.

71. Hobfoll SE, Watson P, Bell CC, et al. Five essential elements of immediate and midterm mass trauma intervention: empirical evidence. Psychiatry 2007;70:283-315.

72. Walter E, Curtis K. The role and impact of the specialist trauma nurse: an integrative review. 7 Trauma Nurs 2015;22:153-69.

73. Lee J. The pill hustle: risky pain management for a gunshot victim. Soc Sci Med 2013;99:162-8

74. Wade D, Crompton D, Howard A, et al. Skills for psychological recovery: evaluation of a post-disaster mental health training program. Disaster Health 2015;2:138-45

75. Patton D, Sodhi A, Affinati S, et al. Post-discharge needs of victims of gun violence in Chicago: a qualitative study. F Interpers Violence 2019;34:135-55.

76. Shaw W, Hong QN, Pransky G, et al. A literature review describing the role of return-to-work coordinators in trial programs and interventions designed to prevent workplace disability. 7 Occup Rehabil 2008;18:2-15.

77. Khan F, Amatya B, Hoffman K. Systematic review of multidisciplinary rehabilitation in patients with multiple trauma. Br 7 Surg 2012;99:88-96.

78. Taichman DB, Bauchner H, Drazen JM, et al. Firearm-related injury and death: a U.S. Health care crisis in need of health care professionals. PLoS Med 2017; 14:e1002430.

79. Stanbrook MB. Gun control: a health issue for which physicians rightfully advocate. CMA7 2019;191:E434-5.

80. Bingenheimer JB, Brennan RT, Earls FJ. Firearm violence exposure and serious violent behavior. Science 2005;308:1323-6.

81. Spitzer SA, Vail D, Tennakoon L, et al. Readmission risk and costs of firearm injuries in the United States, 2010-2015. PLoS One 2019;14:e0209896.

82. Casey R. Disability and unmet health care needs in Canada: a longitudinal analysis. Disabil Health 7 2015;8:173-81.

83. Green B, Horel T, Papachristos AV. Modeling contagion through social networks to explain and predict gunshot violence in Chicago, 2006 to 2014. 7AMA Intern Med 2017;177:326-33.

84. Branas CC, Han S, Wiebe DJ. Alcohol use and firearm violence. Epidemiol Rev 2016;38:32-45.

85. Steenstra IA, Busse JW, Tolusso D, et al. Predicting time on prolonged benefits for injured workers with acute back pain. 7 Occup Rehabil 2015;25:267-78
86. National Electronic Injury Surveillance System (NEISS). Bethesda (MD): U.S. Consumer Products Safety Commission; 2014. Available: http://www. cpsc.gov//Global/Neiss_prod/completemanual\%20.pdf (accessed 2019 July 26).

87. Studdert DM, Zhang Y, Rodden JA, et al. Handgun acquisitions in California after two mass shootings. Ann Intern Med 2017;166:698-706.

88. Wintemute GJ. How to stop mass shootings. N Engl F Med 2018;379:1193-6.

89. Fleegler E. Mass shootings and the numbing of America. FAMA Intern Med 2019;179:610-1.

90. Larsen DA, Lane S, Jennings-Bey T, et al. Spatio-temporal patterns of gun violence in Syracuse, New York 2009-2015. PLoS One 2017;12:e173001.

91. Díez C, Kurland RP, Rothman EF, et al. State intimate partner violencerelated firearm laws and intimate partner homicide rates in the United States, 1991 to 2015. Ann Intern Med 2017;167:536-43.

92. The cost of injury in Canada. Toronto: Parachute; 2015.

93. VanderWeele TJ, Ding P. Sensitivity analysis in observational research: introducing the E-value. Ann Intern Med 2017;167:268-74.

94. VanderWeele TJ, Mathur MB, Ding P. Correcting misinterpretations of the E-value. Ann Intern Med 2019;170:131-2.

95. Haneuse S, VanderWeele TJ, Arterburn D. Using the E-value to assess the potential effect of unmeasured confounding in observational studies. $7 A M A$ 2019;321:602-3

96. Trinquart L, Erlinger AL, Petersen JM, et al. Applying the E-value to assess the robustness of epidemiologic fields of inquiry to unmeasured confounding. Am 7 Epidemiol 2019;188:1174-80.

97. Maa J, Darzi A. Firearm injuries and violence prevention - the potential power of a surgeon general's report. N Engl 7 Med 2018;379:408-10.

98. Bauchner H, Rivara FP, Bonow RO, et al. Death by gun violence - a public health crisis. FAMA 2017;318:1763-4.

99. Matthay EC, Galin J, Rudolph KE, et al. In-state and interstate associations between gun shows and firearm deaths and injuries. Ann Intern Med 2017;167:837-44.

100. Institute of Medicine, National Research Council. Priorities for research to reduce the threat of firearm-related violence. Washington (D.C.): The National Academies Press; 2013. Available: http://www.nap.edu/read/18319 (accessed 2019 Apr. 15).

101. Campion EW, Morrissey S, Malina D, et al. After the mass shooting in Las Vegas - finding common ground on gun control. $N$ Engl $7 \mathrm{Med}$ 2017;377:1679-80.

102. Butkus R, Weissman A. Internists' attitudes toward prevention of firearm injury. Ann Intern Med 2014;160:821-7.

103. Malina D, Morrissey S, Campion EW, et al. Rooting out gun violence. $N$ Engl 7 Med 2016;374:175-6.

104. Cunningham RM, Zimmerman MA, Carter PM. Money, politics and firearm safety. FAMA NetW Open 2019;2:e187823.

105. van Delft-Schreurs CCHM, Van Bergen JJM, De Jongh MAC, et al. Quality of life in severely injured patients depends on psychosocial factors rather than on severity or type of injury. Injury 2014;45:320-6.

106. Garber BG, Rusu C, Zamorski MA, et al. Occupational outcomes following mild traumatic brain injury in Canadian military personnel deployed in support of the mission in Afghanistan: a retrospective cohort study. BMF Open 2016;6:e010780.

107. Goldstick JE, Carter PM, Walton MA, et al. Development of the SaFETy score: a clinical screening tool for predicting future firearm violence risk. Ann Intern Med 2017;166:707-14.

108. Rousseau C, Hassan G, Frounfelker R. The role of physicians in the violence epidemic. CMA7 2019;191:E644.

109. Aronson E. The theory of cognitive dissonance: a current perspective. Adv Exp Soc Psychol 1969;4:1-34.

110. Martz E. Death anxiety as a predictor of posttraumatic stress levels among individuals with spinal cord injuries. Death Stud 2004;28:1-17.

111. Gollwitzer M, Süssenbach P, Hannuschke M. Victimization experiences and the stabilization of victim sensitivity. Front Psychol 2015;6:439.

112. Shaver KG. The attribution of blame: causality, responsibility, and blameworthiness. New York: Springer; 1985.

113. Liebschutz J, Schwartz S, Hoyte J, et al. A chasm between injury and care: Experiences of black male victims of violence. 7 Trauma 2010;69:1372-8.

114. Callebaut L, Molyneux P, Alexander T. The relationship between self-blame for the onset of a chronic physical health condition and emotional distress: a systematic literature review. Clin Psychol Psychother 2017;24:965-86.

Affiliations: Department of Medicine (Raza, Redelmeier), University of Toronto; Evaluative Clinical Sciences (Raza, Thiruchelvam, Redelmeier), Sunnybrook Research Institute; ICES in Ontario (Thiruchelvam); Institute of Health Policy, Management and Evaluation (Redelmeier), Toronto, Ont.

Contributors: Donald Redelmeier wrote the first draft. Sheharyar Raza and Donald Redelmeier contributed to study design and background scholarship. All authors contributed to manuscript preparation, data analysis, results interpretation, critical revisions and the final decision to 
submit. All authors provided final approval of the version to be published. All authors agreed to be accountable for all aspects of the work.

Funding: This project was supported by a Canada Research Chair in Medical Decision Sciences, the Canadian Institutes of Health Research, and the PSI Foundation of Ontario. The funding organizations had no role in the design and conduct of the study; collection, management, analysis or interpretation of the data; and preparation, review or approval of the manuscript.

Acknowledgments: The authors thank the following for their helpful comments: Leonard Evans, Fizza Manzoor, Robert Redelmeier, Filippo Raso, Lee Ross, Charles Tator and Albert Wu.

Data sharing: The data set from this study is held securely in coded form at ICES. While data sharing agreements prohibit ICES from making the data set publicly available, access may be granted to those who meet prespecified criteria for confidential access, available at www.ices.on.ca/DAS. The full data set creation plan and underlying analytic code are available from the authors upon request, understanding that the computer programs may rely upon coding templates or macros that are unique to ICES and are therefore either inaccessible or may require modification. Patient privacy laws prohibit making individual-level data publicly available. Aggregate data are shown in the paper and Appendix 1. Researchers interested in replicating or extending the work can seek access to individuallevel data through ICES (www.ices.on.ca).

Supplemental information: For reviewer comments and the original submission of this manuscript, please see www.cmajopen.ca/content $/ 8 / 3$ / E469/suppl/DC1.

Disclaimer: This study was supported by ICES, which is funded by an annual grant from the Ontario Ministry of Health and Long-Term Care (MOHLTC). The opinions, results and conclusions reported in this article are those of the authors and are independent from the funding sources. No endorsement by ICES or the Ontario MOHLTC is intended or should be inferred. 